\title{
A Look at Flexibilities and Elasticities
}

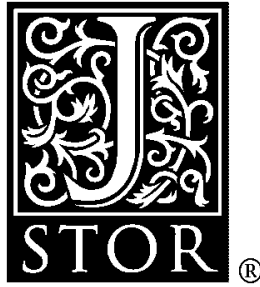

James P. Houck

Journal of Farm Economics, Vol. 48, No. 2. (May, 1966), pp. 225-232.

Stable URL:

http://links.jstor.org/sici?sici=1071-1031\%28196605\%2948\%3A2\%3C225\%3AALAFAE\%3E2.0.CO\%3B2-J

Journal of Farm Economics is currently published by American Agricultural Economics Association.

Your use of the JSTOR archive indicates your acceptance of JSTOR's Terms and Conditions of Use, available at

http://www.jstor.org/about/terms.html. JSTOR's Terms and Conditions of Use provides, in part, that unless you have obtained prior permission, you may not download an entire issue of a journal or multiple copies of articles, and you may use content in the JSTOR archive only for your personal, non-commercial use.

Please contact the publisher regarding any further use of this work. Publisher contact information may be obtained at http://www.jstor.org/journals/aaea.html.

Each copy of any part of a JSTOR transmission must contain the same copyright notice that appears on the screen or printed page of such transmission.

The JSTOR Archive is a trusted digital repository providing for long-term preservation and access to leading academic journals and scholarly literature from around the world. The Archive is supported by libraries, scholarly societies, publishers, and foundations. It is an initiative of JSTOR, a not-for-profit organization with a mission to help the scholarly community take advantage of advances in technology. For more information regarding JSTOR, please contact support@jstor.org. 


\title{
A Look at Flexibilities and Elasticities*
}

\author{
JaMes P. Houck
}

\begin{abstract}
Economists have developed a carefully reasoned network of theoretical restrictions applying to price and income elasticities of demand. Yet, because supplies of many farm-produced commodities are fixed in the short run, agricultural economists often find that price flexibilities are more useful and easier to measure empirically, especially in marketwide situations. Theoretical restrictions on demand elasticities imply a complete, largely unexplored set of corresponding restrictions among price flexibilities. These flexibility conditions apply to column sums, row sums, and cross-coefficient symmetry within a multicommodity flexibility matrix. As with elasticities, the theoretical relationships among price flexibilities have implications for applied research.
\end{abstract}

$I^{\mathrm{N}}$ N PURE FORM, demand theory begins with utility-maximizing reactions of individual buyers to prices and incomes which they consider as given. Their scope of economic behavior is limited to decisions on quantities demanded. Demand elasticities measure their quantity reactions to changing prices and income. Over the years, economists have developed a carefully reasoned network of theoretical restrictions which apply to direct and cross price elasticities and income elasticities of demand [3;6, chaps. 6-7]. Although these relationships strictly apply only to individuals, they are often taken as approximations in marketwide analyses. G. E. Brandow, for example, used them to estimate complete elasticity matrices for large blocks of U.S. farm commodities [1].

Elasticities long have been the basic conceptual tools both in demand theory and in estimation. Yet agricultural economists often find that price flexibilities are more useful and easier to measure, especially in marketwide situations. Price flexibility is the percentage of change in the price of a commodity, associated with an isolated 1-percent increase in the quantity sold or in a related variable. The term, used in this way, was introduced in 1919 by H. L. Moore in his pioneering article, "Empirical Laws of Demand and Supply and the Flexibility of Prices" [4]. Moore drew attention to price flexibilities in order (a) to focus on price phenomena from the producers' viewpoint and (b) to provide analytic content to his cotton-demand-curve estimates. The concept's modern usefulness grows out of Moore's observation that, although individuals make quantity decisions based on given prices, market supplies of many agricultural products are so fixed in the short run that prices must bear the entire adjustment burden. Conse-

* Misc. J. Ser. 1241, Minnesota Agr. Exp. Sta. Helpful comments were offered by F. V. Waugh and A. S. Rojko of the USDA and W. K. Bryant and J. W. Hammond of the University of Minnesota.

JAMES P. HodCK is assistant professor of agricultural economics, University of Minnesota. 
quently, the amount by which market prices change in response to output changes between production periods is particularly important in the farm sector.

In this setting, the straightforward application of multiple regression often is appropriate for the estimation of short-run demand. Quantities produced, income, and other "shifters" can be used as independent variables with market price as the dependent variable. When data are expressed in logarithms, the regression coefficients can be viewed as price-flexibility estimates.

The widespread use of price flexibilities in empirical agricultural economics research is illustrated in the 1962 compilation of estimated demand and supply functions by Buchholz, Judge, and West [2]. Of about 200 U.S. agricultural-product demand equations reprinted, approximately 100 were estimated in terms of price flexibilities. Although the theory of demand elasticities is virtually complete, very little analysis is available on the logical relationships to be expected among price flexibilities. The purpose of this article, therefore, is to show with matrix algebra that the established theoretical relationships among demand elasticities imply a complete, largely unexplored set of corresponding restrictions among price flexibilities. Recently, F. V. Waugh developed a set of price-flexibility conditions $d i$ rectly from an $n$-equation general equilibrium model in which each price was expressed as a function of all quantities and income [5, pp. 80-84]. Most of his findings agree with those presented here, but some do not. The differences arise because Waugh began with demand equations which had prices on the left of the equality sign, and this analysis begins from traditional elasticity restrictions imposed on demand functions when quantities are on the left.

The major elasticity relations shown to have counterparts among price flexibilities involve column sums, row sums, and cross-coefficient symmetry. ${ }^{1}$ The compact notation of matrix algebra facilitates this discussion without obscuring the fundamental relationships which emerge. A simple numerical example, using hypothetical figures, is presented to illustrate the paper's major conclusions.

\section{A Simplified Commodity System in Matrix Algebra}

First consider an $n$-commodity system in which the quantities demanded of each good are expressed as functions of all retail prices in the system and income. For simplicity, ignore the difficult problems of aggregation and income distribution. Assume that preferences are constant. This system can be written

\footnotetext{
${ }^{1}$ In this article, the term "cross price flexibility" will mean the percentage of change in a good's price associated with an isolated 1-percent increase in the quantity demanded of another good.
} 


$$
\mathrm{q}^{\prime}=\mathrm{Ep}^{\prime}+\mathrm{a}^{\prime} \mathrm{y}^{*}
$$

where $q$ is a logarithmic row vector of $n$ per capita quantities demanded: $\mathrm{q}=\left[\log \mathrm{q}_{1}, \log \mathrm{q}_{2}, \cdots, \log \mathrm{q}_{\mathrm{n}}\right]$. Let $p$ be a similar row vector of $n$ retailprice logarithms, one for each commodity in appropriate order. ${ }^{2}$ Let $\mathrm{E}$ be an $n \times n$ matrix of direct and cross price elasticities of demand. Let $a$ be an ordered row vector of $n$ income elasticities. Finally, let $\mathrm{y}^{*}$ be a logarithmic scalar measuring per capita disposable income. ${ }^{3}$

Consider two other row vectors, $r$ and $c$. The vector $r$ is an ordered set of $n$ expenditure weights, one for each commodity. Each element in $r$ is the proportion of total expenditures spent on the corresponding commodity at given prices and income. Others have shown that the expenditure-weighted sum of income elasticities is $+1.0[6, p .112]$, so that

$$
\operatorname{ar}^{\prime}=1 \text {. }
$$

The vector $c$ consists of $n$ ones: $\mathrm{c}=[1,1,1, \ldots, 1]$. It can be used to add columns and rows of other matrices. For example, since $r$ is an exhaustive vector of expenditure proportions, then

$$
\mathrm{rc}^{\prime}=1 .
$$

Equation (1) may be manipulated into a form useful for considering price flexibilities:

$$
\mathrm{p}^{\prime}=\mathrm{E}^{-1} \mathrm{q}^{\prime}-\mathrm{E}^{-1} \mathrm{a}^{\prime} \mathrm{y}^{*}
$$

or

$$
\mathrm{p}^{\prime}=\mathrm{Fq}^{\prime}-\mathrm{Fa}^{\prime} \mathrm{y}^{*}
$$

where $\mathbf{F}=\mathbf{E}^{-1}$, and $\mathbf{F}$ is the $n \times n$ matrix of price flexibilities with respect to quantities demanded. Given the established theoretical restrictions on the elements of $\mathbf{E}$ and $a$, what can be said about the elements of $\mathbf{F}$ and $\mathrm{Fa}^{\prime}$ ?

\section{Flexibility Column Sums}

A basic restriction on $\mathbf{E}$ is that the expenditure-weighted sum of any $i$ th column of $\mathbf{E}$ is equal to the negative proportion of total expenditures accounted for by the $i$ th good $[6$, p. 112]. In matrix terms,

$$
\mathrm{rE}=-\mathrm{r} .
$$

\footnotetext{
2 One of the elements in $p$ may be regarded as a price index of all items outside the sector under study, say all nonfood prices. An element in $q$ may be a similar quantity index of outside items $[1$, p. 13].

In order to sidestep theoretical difficulties involved in comparing demand elasticities with respect to expenditures and demand elasticities with respect to disposable income, assume that expenditures remain a constant proportion of disposable income. Then the two elasticities are equal $[6$, p. 220].
} 
This restriction carries over directly to the flexibility matrix. Post-multiplying (5) by $\mathrm{E}^{-1}$ (which equals $\mathbf{F}$ ), we find that

$$
\mathrm{r}=-\mathrm{rF} \quad \text { or } \quad \mathrm{rF}=-\mathrm{r} .
$$

Thus, the column-sum condition for the flexibility matrix is exactly the same as the corresponding elasticity restriction. This result agrees with Waugh's column-sum condition. It could be useful in estimating or computing a complete flexibility matrix for a group of related commodities as Brandow has done $[1$, p. 65].

\section{Flexibility Row Sums and Homogeneity}

To fulfill the zero-degree-homogeneity condition of demand theory, the sum of direct and cross price elasticities for a given commodity must equal the negative of its income elasticity [6, p. 111]. Thus, if all prices and incomes change by the same proportion, no change will occur in the quantities demanded. This restriction can be written

$$
\mathrm{Ec}^{\prime}=-\mathrm{a}^{\prime} \text {. }
$$

Pre-multiplying by $\mathrm{E}^{-1}$ (which is $\mathbf{F}$ ) and recalling that $\mathrm{c}$ is a row vector of ones, we find that

$$
\mathrm{c}^{\prime}=-\mathrm{Fa}^{\prime} .
$$

Hence, the negative of each weighted row sum of $F$ is +1.0 when the weights are corresponding income elasticities.

Compare equation (8) with the coefficient of $\mathrm{y}^{*}$ in (4). It appears that when the homogeneity condition holds for elasticities, then each price flexibility with respect to income (or total expenditures) must be +1.0 . Thus, if disposable incomes increase by a given percentage and all quantities remain fixed, then each price will be bid up by the same percentage so that original relationships among prices and income are maintained. Equation (4) can be written as

$$
\mathrm{p}^{\prime}=\mathrm{Fq}^{\prime}+\mathrm{c}^{\prime} \mathrm{y}^{*} .
$$

This condition suggests that when price is the dependent variable and quantities are independent variables in a logarithmic regression equation, then income (or total expenditures) theoretically can be entered with a +1.0 coefficient if all competing commodities appear in the equation and nothing special is stipulated about the distribution of income changes. Although these conditions may not apply in any given empirical research problem, equation (9) does suggest that the meaning and use of estimated price flexibilities with respect to income should be re-examined.

Meaningful interpretation of an estimated price flexibility on income is elusive, especially if it differs widely from +1.0 . When zero-degree homo- 
geneity is assumed among prices, income, and quantities demanded, the flexibility coefficient on income is not a behavioral measure in the same sense as the income elasticity. For example, a regression estimate quite different from +1.0 may indicate that important competing or complementary products were omitted, that tastes and preferences systematically changed, or that supply fixity may not apply to all important goods in the analysis. Moreover, direct and cross flexibility coefficients with respect to quantities in a regression equation might vary significantly depending upon whether the income coefficient is determined jointly with the others or is fixed at some level, say +1.0.

This view of the price-flexibility coefficient on income differs from Waugh's [5, p. 83]. Waugh implicitly applied Euler's Theorem to his demand equations in such a way that a constant percentage increase in both quantities and income produce no price changes. ${ }^{4}$ If this view of homogeneity is taken, then Waugh's results follow. But if the traditional homogeneity assumption is made, then equation (9) follows.

\section{Symmetry Among Cross Flexibilities}

The important symmetry relation between cross elasticities in $\mathbf{E}$ can be written as

$$
e_{i j}=\frac{r_{j}}{r_{i}} e_{j i}+r_{j}\left(a_{j}-a_{i}\right)
$$

where $e_{i j}$ is the cross elasticity at the intersection of the $i$ th row and $j$ th column of $\mathbf{E}$ and is the percentage change in the quantity of $i$ demanded given an isolated 1-percent increase in the price of $j[1, p .13]$. The $a_{j}$ and $a_{i}$ are income elasticities. If the income elasticities are similar and the expenditure proportions small, then

$$
\mathrm{e}_{\mathrm{ij}} \sim \frac{\mathrm{r}_{\mathbf{j}}}{\mathrm{r}_{\mathrm{i}}} \cdot \mathrm{e}_{\mathrm{ji}}
$$

By adding a bit more notation, we can express the exact symmetry relation in (10) as a single matrix equation for the whole $n$-commodity system. Let $\mathrm{R}$ be an $n \times n$ diagonal matrix with individual expenditure proportions in appropriate order down the main diagonal. It then follows that

$$
\mathrm{E}=\mathrm{R}^{-1} \mathrm{E}^{\prime} \mathrm{R}+\mathrm{AR}
$$

where $A=\left(c^{\prime} \mathbf{a}-a^{\prime} c\right)$. Pre- and post-multiplying $E^{\prime}$ by $R^{-1}$ and $R$ respectively yields the equation (10) quotient of the expenditure ratios times the cross-elasticity coefficient. Post-multiplying $\mathbf{A}$ by $\mathbf{R}$ provides the $j$ th ex-

4 This point was clarified in correspondence and conversation with Dr. Waugh. 
penditure proportion multiplied by the income-elasticity difference between $\operatorname{good} j$ and $\operatorname{good} i$. Note that each diagonal element of $\mathrm{A}$ is zero, so that

$$
\mathrm{e}_{\mathrm{ii}}=\frac{\mathrm{r}_{\mathrm{i}}}{\mathrm{r}_{\mathrm{i}}} \mathrm{e}_{\mathrm{ii}}-0
$$

Thus, equation (12) expresses the complete symmetry relation among all elasticities. This equation can be manipulated to give a comparable expression in flexibilities by noting again that $\mathbf{E}^{-1}=\mathbf{F}$, and, therefore, that $\left(E^{\prime}\right)^{-1}=F^{\prime}$. Rearranging (12), we get

$$
\mathrm{R}^{-1} \mathrm{E}^{\prime} \mathrm{R}=\mathrm{E}-\mathrm{AR} \text {. }
$$

Post-multiplying by $R^{-1} F^{\prime} R$ gives

$$
\mathrm{I}=\mathrm{ER} \mathrm{R}^{-1} \mathrm{~F}^{\prime} \mathrm{R}-\mathrm{AF^{ \prime }} \mathrm{R} .
$$

Pre-multiplying by $\mathbf{F}$ gives

$$
\mathrm{F}=\mathrm{R}^{-1} \mathrm{~F}^{\prime} \mathrm{R}-\mathrm{FAF} \mathrm{F}^{\prime} \mathrm{R}
$$

Looking at $\mathrm{FAF}^{\prime}$ a little more closely, we find that

$$
\mathrm{FAF}^{\prime}=\mathrm{F}\left(\mathrm{c}^{\prime} \mathrm{a}-\mathrm{a}^{\prime} \mathrm{c}\right) \mathrm{F}^{\prime}
$$

From equation (8) we recall that $\mathrm{Fa}^{\prime}=-\mathrm{c}^{\prime}$ and, similarly, that $\mathrm{aF}^{\prime}=-\mathrm{c}$. Therefore

$$
\mathrm{FAF}=\left(\mathrm{c}^{\prime} \mathrm{cF}^{\prime}-\mathrm{Fc}^{\prime} \mathrm{c}\right)
$$

Because $\mathrm{c}^{\prime} \mathrm{c}$ is a complete $n \times n$ matrix of ones, $\mathrm{FAF}^{\prime}$ is an $n \times n$ matrix with zeros down the diagonal. Each off-diagonal element is the difference between two row sums of $\mathrm{F}$. That is, the $i j$ th cell of $\mathrm{FAF}^{\prime}$ contains the difference between the sums of the $j$ th row and the $i$ th row of $F$. In terms of individual flexibilities,

$$
f_{i j}=\frac{r_{j}}{r_{i}} f_{j i}-r_{j}\left[\sum_{k=1}^{n} f_{j k}-\sum_{k=1}^{n} f_{i k}\right] .
$$

This is exactly comparable to the symmetry relation for price elasticities in equation (12), since each income elasticity is equal to the negative of the price-elasticity row sum for that good when zero-degree homogeneity holds. However, no simple interpretation of the flexibility row sum appears except as a commodity's net price change when all quantities in the system are increased by 1 percent. This result differs from Waugh's exact-symmetry condition because of the differing homogeneity assumptions.

In any case, if the flexibility row sums are similar and the expenditure proportions small, then

$$
f_{i j} \sim \frac{r_{j}}{r_{i}} f_{j i}
$$


This approximate symmetry relation is similar to that for cross elasticities, equation (11), and agrees with Waugh's approximate flexibility relation. In situations where the approximate symmetry relation is appropriate, equations (11) and (19) indicate that the ratio of any two cross flexibilities is approximately equal to the ratio of the two corresponding cross elasticities and to the reciprocal ratio of expenditure proportions for the two commodities. That is,

$$
\frac{\mathrm{f}_{\mathrm{ij}}}{\mathrm{f}_{\mathrm{ji}}} \sim \frac{\mathrm{e}_{\mathrm{ij}}}{\mathrm{e}_{\mathrm{ji}}} \sim \frac{\mathrm{r}_{\mathrm{j}}}{\mathrm{r}_{\mathrm{i}}} .
$$

Both the exact and the approximate symmetry relations for flexibilities could be useful for estimating specific unknown cross-flexibility coefficients from available data or for developing, in conjunction with other restrictions, a multicommodity flexibility matrix.

\section{An Example}

This numerical example can be used to illustrate these algebraically demonstrated relationships. The $3 \times 3$ matrix, $E$, represents a hypothetical price-elasticity matrix with negative direct elasticities and smaller positive cross elasticities. The income elasticities are represented by $a$ and a set of expenditure proportions by $r$.

$$
\mathrm{E}=\left[\begin{array}{rrr}
-1.8 & .3 & .0 \\
.6 & -1.3 & .1 \\
.2 & .3 & -1.5
\end{array}\right] \quad \mathrm{r}=\left[\begin{array}{lll}
.4 & .5 & .1
\end{array}\right]
$$

This matrix and the two row vectors were chosen so as to fulfill the column-sum, row-sum, and symmetry conditions of equations (5), (7), and (10), as well as the additional restrictions indicated by (2) and (3). Matrix $\mathbf{F}$ is the inverse of $\mathbf{E}$.

$$
\mathrm{F}=\left[\begin{array}{lll}
-.604 & -.141 & -.009 \\
-.289 & -.849 & -.057 \\
-.138 & -.189 & -.679
\end{array}\right]
$$

Since the elasticity matrix shows none of the three commodities exhibiting complementarity, $\mathbf{F}$ is entirely negative, with negative direct flexibilities down the main diagonal and smaller negative cross flexibilities in offdiagonal cells. The reader may use $\mathbf{F}$ together with $a$ and $r$ to verify the flexibility column-sum, row-sum, and symmetry conditions of equations (6), (8), and (18), respectively.

For instance, consider the column-sum condition of equation (6) applied to the first column of $\mathrm{F}$ :

$$
r_{1} f_{11}+r_{2} f_{21}+r_{3} f_{31}=-r_{1} .
$$


Inserting the example figures and allowing for slight rounding errors, we get

$$
\begin{aligned}
-.242-.144-.014 & =-\mathrm{r}_{1} \\
& =-.4 .
\end{aligned}
$$

As another illustration, consider the symmetry relation between $f_{12}$ and $f_{21}$. The exact relation of equation (18) indicates that

$$
f_{12}=\frac{r_{2}}{r_{1}} f_{21}-r_{2}\left[\left(f_{21}+f_{22}+f_{23}\right)-\left(f_{11}+f_{12}+f_{13}\right)\right] .
$$

Inserting the sample figures and allowing for rounding errors, we get

$$
\begin{aligned}
\mathrm{f}_{12} & =\frac{.5}{.4}(-.289)-.5[(-1.195)-(-.754)] \\
& =-.361+.220 \\
& =-.141 .
\end{aligned}
$$

\section{Concluding Comments}

These relationships among price flexibilities are deduced directly from restrictions imposed on elasticities by traditional demand theory, in which many individual buyers, each with a budget constraint, react to prices they consider given. But when total quantities are fixed, then market prices bear the adjustment burden. Flexibility coefficients, both direct and cross, become meaningful in measuring (a) the responsiveness of a commodity's price to changes in its output and (b) the impact throughout the entire price network of output changes in one or more commodities. In agricultural economics, such measurements are especially useful.

\section{References}

[1] Brandow, G. E., Interrelations Among Demands for Farm Products and Implications for Control of Market Supply, Pennsylvania State Agr. Exp. Sta. Bul. 680, 1961.

[2] Buchrolz, H. E., G. G. Judge, AND V. I. West, A Summary of Estimated Behavior Relations for Agricultural Products in the United States, Res. Rep. AERR-57, Department of Agricultural Economics, University of Illinois, 1962.

[3] Frisch, R., "A Complete Scheme for Computing All Direct and Cross Elasticities in a Model with Many Sectors," Econometrica, 27:177-196, April 1959.

[4] Moore, H. L., "Empirical Laws of Demand and Supply and the Flexibility of Prices," Pol. Sci. Quart. 34(4): 546-567, 1919.

[5] WAdgh, F. V., Demand and Price Analysis: Some Examples from Agriculture, USDA Tech. Bul. 1316, 1964.

[6] Wold, H., and Lars Juréen, Demand Analysis, New York, John Wiley and Sons, Inc., 1955. 